QUEIROLO, Graciela Amalia (2018). Mujeres en las oficinas: trabajo, género y clase en el sector administrativo (Buenos Aires, 1910-1950).

Buenos Aires: Biblos, 269 págs.

María Laura GIUDICI NAVARRO

Avances del Cesor, V. XVI, No 21, diciembre 2019, pp. 225-228.

ISSNe 2422-6580 / ISSN 1514-3899 - http://web2.rosario-conicet.gov.ar/ojs/index.php/AvancesCesor/index

\title{
Graciela Amalia Queirolo. Mujeres en las oficinas: trabajo, género y clase en el sector administrativo (Buenos Aires, 1910-1950). Buenos Aires: Biblos, 2018, 269 páginas.
}

\section{María Laura Giudici Navarro Universidad Nacional de Rosario navarro.mlaura@gmail.com} (Argentina)

Las oficinas existen en el imaginario de nuestra sociedad contemporánea como un espacio masculino donde circulan hombres blancos y heterosexuales, vestidos con trajes refinados y zapatos pulidos. Mientras ellos imparten órdenes a diestra y siniestra, las mujeres pululan a su alrededor, escuchando y acatando con la pericia digna de féminas educadas y elegantes, que alcanzan la eficiencia desde la invisibilidad del decorado. Si intentamos construir una imagen de las oficinas a mitad del siglo pasado, todo parecería girar en torno a estos hombres dignos del sueño americano. A su lado, se dibujaría una zona invisible/invisibilizada donde otras representaciones étnicas y sexo-genéricas se construyen como lo abyecto y son obligadas a vivir en las sombras -al menos que logren ser leídas desde el afuera, con categorías impuestas por los sujetos que deciden quién ingresa dentro del límite de lo legible y quién permanece en el reino de las penumbras-. Parafraseando a Max Horkheimer, ¿no podríamos decir entonces que la labor fundamental del historiador es llevar adelante una investigación crítica que logre iluminar la oscuridad de los desconocidos por la historia oficial? Es aquí donde yace la importancia de este libro.

Mujeres en las oficinas es el producto de la tesis doctoral de Graciela A. Queirolo. Este libro es una contundente muestra de su trayectoria y destreza para trabajar metodológicamente diferentes tipos de fuentes, los cuales resultan esenciales para la descripción, comparación $\mathrm{y}$ análisis- tanto cualitativo como cuantitativo- de su objeto de estudio, así como para la construcción de su hipótesis sobre las mujeres blancas del sector administrativo. El resultado deviene sumamente enriquecedor para los lectores, quienes pueden distinguir procesos de 
ruptura y continuidad viendo delinearse a la par a un grupo social y sexo-genérico que se separa de la excepcionalidad que algunas indagaciones y sentidos sociales le han impreso.

Desde el comienzo, la autora establece su objetivo: investigar la participación de las mujeres en el sector administrativo a lo largo de cuarenta años. Asimismo, construye como hilo conductor una tríada que liga la feminización de las tareas administrativas, con la dialéctica de retroalimentación entre las concepciones sociales y la elaboración de estos nuevos estereotipos, y los mecanismos de inequidad salarial que siguen siendo operativos hasta la actualidad. Con la Buenos Aires de la modernización capitalista como telón de fondo, y siendo las décadas de 1910 a 1950 la periodización escogida, la autora nos muestra cómo las mujeres incrementaron su participación en empleos administrativos que comenzaron a crecer a la par del desarrollo del sector burocrático al interior de la industria, el comercio y la banca. De este modo, la mujer administrativa aparecía indiscutiblemente como un sujeto urbano, alfabetizado y con acceso a una capacitación brindada por institutos privados, tales como las Academias Pitman.

A lo largo de los párrafos que componen la introducción, Queirolo realiza un punteo claro y conciso sobre los temas a profundizar en los capítulos subsiguientes. Comienza con un apartado general, donde enmarca a su objeto de estudio dentro del contexto histórico que posibilitó y requirió su surgimiento, junto con los estereotipos e inequidades que conformaron lo que ella denomina como la paradoja de la empleada. Más adelante se encarga de desarrollar una breve crítica a la historiografía clásica laboral y a los estudios sobre la clase media, donde reconoce los aportes de estos análisis y hecha luz sobre algunas de sus falencias. Así sugiere que ninguno de los dos campos fue capaz de prestarle la necesaria atención al sector abordado en este libro, sino que se concentraron solamente en las mujeres obreras $\mathrm{o}$ administrativas, pero sin vislumbrar las paradojas propias a su posición laboral, de género y clase. Es por ello que la autora elige priorizar el análisis de los sentidos y representaciones sociales; sin embargo, hace mea culpa al declarar como deuda la integración de la mirada étnica $\mathrm{y}$ de las subjetividades de las protagonistas.

En el primer capítulo, se analiza el contexto histórico y económico mundial y local, donde el incremento en el número de los puestos de trabajo fue resultado de la expansión y modernización capitalista a gran escala. La diversificación de la estructura productiva dio lugar al surgimiento de gran cantidad de ocupaciones nuevas, así como a divisiones en el interior de los campos tradicionales de empleo. La autora demuestra cómo las empleadas administrativas lograron constituir progresivamente, y manteniendo un crecimiento constante, un segmento laboral integrado por ocupaciones variadas. $\mathrm{La}$ oficina moderna fue el núcleo de esta transformación y, en consecuencia, la describe listando desde su organigrama hasta los nuevos saberes técnicos y científicos. Asimismo, desde este espacio Queirolo nos introduce en la paradoja de la empleada, donde el factor de clase y las especificidades del sector administrativo se combinan con contradicciones de género, tales como las segregaciones horizontal y vertical. Por ello, la hipótesis propuesta señala que dentro de este periodo de transformación económica y social, los procesos de construcción de identidades laborales se sustentaron tanto en factores positivos como el logro de cierto prestigio social por parte de las oficinistas, así como en situaciones desventajosas tales como la "brecha 
salarial", el "techo de cristal" y la "doble jornada laboral". La ideología de la domesticidad y la excusa de excepcionalidad son señaladas como aquellas que justificaron la réplica en el ámbito laboral de los llamados contratos sexual y matrimonial.

Continuando con estos lineamientos, en el siguiente capítulo la autora desarrolla como tema central la idea del ángel de la oficina. Para ello, demarca como objetivos el análisis cuantitativo del ingreso de mujeres al sector administrativo y la observación de las concepciones sociales que operaron en la feminización de tres ocupaciones administrativas destacadas: dactilógrafa, taquígrafa-dactilógrafa y secretaria. Para alcanzar el primero, Queirolo realiza un exhaustivo análisis de fuentes, principalmente censos, y discute con otros autores como Gino Germani y Ernesto Kritz. La reformulación de la concepción de la mujer como el ángel del hogar dentro del ámbito laboral, dio como resultado la feminización de aquellos tres empleos. Apelando a las supuestas capacidades inherentes a su género, se dio un proceso de devaluación de la capacitación profesional adquirida por las mujeres y de justificación de las inequidades laborales a las que eran sometidas, sin reparar en los procesos sociales que ejecutaron la educación de los cuerpos femeninos en aquellas habilidades sociales.

A lo largo del tercer capítulo, la autora indaga sobre los distintos aparatos de formación educativa, partiendo de la importancia de la expansión de la alfabetización primaria formal brindada por el Estado y haciendo especial hincapié en las instituciones informales privadas, que comienzan a poblar la ciudad. La promesa de éxito y de ascenso social son los ejes publicitarios para atraer nuevas clientas. Sin embargo, Queirolo trabaja desde el desvío y las contradicciones al resaltar como hipótesis que esta capacitación profesional, no sólo no borró las inequidades socio-genéricas, sino que las acentuó.

Con los procesos masificados de profesionalización, estos saberes se transformaron en condiciones imprescindibles. Poco a poco, la idea imperiosa de contar con ciertos conocimientos ante excepcionalidades y contingencias, llevaron a que el segmento femenino ingresara cada vez más al mercado de profesionalización, sin por ello abandonar sus capacidades y obligaciones domésticas. El trabajo femenino fue promovido en base a la noción de complementariedad, lo cual justificaba la conservación de las inequidades laborales y salariales en contraste con la población masculina. Academias como las Pitman, desarrollaron estrategias diferenciales para la atracción de los distintos segmentos sexo-genéricos, apelando al "líder" masculino y a las cualidades "inherentemente" femeninas, como orden, mesura, dedicación y buena presencia.

En el anteúltimo capítulo Queirolo aborda la formación y el funcionamiento, en perspectiva comparada, de los dos sindicatos más importantes de esta época para las empleadas de escritorio: la Federación de Empleados de Comercio (FEC) y la Federación de Asociaciones Católicas de Empleadas (FACE). La autora analiza estas organizaciones a partir de su desarrollo, las técnicas operativas y sus vínculos con el socialismo y el peronismo. $\mathrm{Si}$ bien ambos sindicatos operaban de manera distinta- con grandes divergencias ideológicas y estratégicas- los dos encauzaban la participación femenina dentro del mercado de trabajo desde la necesidad económica y la eventualidad. A pesar de que los conflictos de género eran conocidos por los sindicatos, la elección 
política consistía en dejarlos en segundo plano. De este modo, podemos vislumbrar cómo las organizaciones sindicales funcionaron apologéticamente dentro del sistema de explotación diferencial.

A lo largo del quinto capítulo, Queirolo explora con detenimiento dos estereotipos sexo-genéricos y de clase que se instalaron ampliamente en los discursos sociales y las representaciones gráficas. La autora logra recuperarlos a través del análisis de revistas y prensa periódica. En estas fuentes documentales aparecían referencias recurrentes al hada del teclado y a la empleada oprimida. La primera era ridiculizada por la prensa como un ser negligente, caprichoso y sólo interesado en la carrera matrimonial. En cambio, la otra era la víctima de un "mal paso", que la había llevado a la degradación femenina a partir de una sexualidad pervertida. Sin embargo, en ambos casos subyacían dos supuestos: que el tránsito por el espacio público era temporal, y que ambas caracterizaciones desprestigiaban el valor social y económico de sus trabajos. Según la autora, son estos dos estereotipos los que generaron las condiciones de posibilidad para la construcción de sentidos sobre la presencia femenina en el sector burocrático. Asimismo, esta se configuraba de manera espejada al mercado matrimonial, siendo la subordinación al varón la constante en ambos ámbitos. Sin embargo, escritoras como Alfonsina Storni y Josefina Marpons son retomadas para demostrar la existencia de posiciones disidentes. Para finalizar, Queirolo subraya la importancia del campo cultural en la construcción de las representaciones sobre el cuerpo femenino y como la profesionalización diferencial, sumada a los debidos mandatos domésticos y maternales, fue forjando subjetividades y sentidos funcionales a la lógica socio-económica que necesita- ba este sector poblacional para sobrellevar los cambios económicos del momento.

Queirolo invita a leer desde una perspectiva histórica a un sector que influyó ampliamente en el ámbito laboral y en la construcción de imaginarios y representaciones sexo-genéricas, y nos permite ver cúan vivas se mantienen las contradicciones: el trabajo de la autora es un llamamiento discreto a no dejar atraparse por el acostumbramiento a los procesos cotidianos y de larga data sobre la manipulación económica y la explotación laboral para con todos los grupos que puedan caer presos de la abyección totalizadora y masculinizante. Las continuidades y desviaciones se funden en las multiplicidades, y es por ello que debemos sumergirnos en las páginas de este libro para rescatar las resistencias, pasadas y presentes, ante la apatía derrotista de la explotación capitalista y heteropatriarcal.

\author{
Recibido: 05-03-2019 \\ Aceptado: 05-07-2019 \\ Publicado: 04-12-2019
}

